\title{
Evaluation of Sampling Protocol for i-Tree Eco: A Case Study in Predicting Ecosystem Services at Auburn University
}

\author{
Nicholas A. Martin, Arthur H. Chappelka, Greg Somers, Edward F. Loewenstein, \\ and Gary J. Keever
}

\begin{abstract}
Auburn University (Auburn, Alabama, U.S.) was used as a site for a case study evaluating the standard plot sampling protocol for i-Tree Eco. A $100 \%$ tree inventory of the managed areas of campus was conducted in 2009-2010 and provided a complete data set for the evaluation. Air pollution removal, carbon storage, and carbon sequestration were the ecosystem services examined. Total tree population was also utilized for this assessment to provide a comparison to i-Tree Eco protocol. To achieve an estimate with a $\pm 10 \%$ allowable error of the total campus value, 622 plots $(0.04$ ha each) with at least one tree present would need to be inventoried for air pollution removal, 870 plots for carbon storage, 483 plots for carbon sequestration, and 258 plots for number of trees, as opposed to the standard i-Tree Eco protocol of 200 plots. This study provides a first step in evaluating i-Tree Eco sampling protocol; however, efforts testing these results at sites throughout the southern United States are needed to provide the most accurate estimate of plot numbers necessary for predicting ecosystem services of urban forests.

Key Words. Alabama, i-Tree Eco; Plot Sampling; UFORE Model; Urban Tree Inventory.
\end{abstract}

In the current urban environment, transformations take place every day, many of which impact the urban forest. It is critical for urban forest managers to recognize these changes and their impacts, and be able to evaluate them in the future. Tree inventories are conducted and analyzed to provide information regarding urban forest structure and function, to support urban forest resource management and to evaluate environmental changes.

Traditionally, information on urban forest structure has been gathered on street and park trees (McBride and Nowak 1989; Hauer et al. 1994; Welch 1994), but as management objectives change to include environmental services, inventories have been expanded to encompass vegetation in other parts of the urban forest. These include residential, industrial, and abandoned lands (McPherson et al. 1997). Besides being implemented to provide structural information (e.g., tree species, number, size and/ or age, location) (Nowak and Crane 1998; Nowak et al. 2008a; Nowak et al. 2008b), inventories are also the basis for deriving measurements of ecosystem services, including carbon storage, carbon sequestration, and energy savings (Nowak et al. 2008a).

Several methods have been used to conduct urban tree inventories, including sampling (Nowak and Crane 1998; Nowak et al. 2008a; Nowak et al. 2008b) and 100\% inventories (Martin 2011). Sampling is conducted by collecting data on a predetermined number of trees or plots within a given area to provide an estimate of a larger area (McBride and Nowak 1989; Jaenson et al. 1992; Nowak et al. 2008a; Nowak et al. 2008b). Using 100\% inventories every tree is located and data are recorded, providing the most accurate information (Jaenson et al. 1992; Nowak et al. 2008a). However, unless this inventory is being conducted on a relatively small area, it may not be as efficient as sampling (Jaenson et al. 1992; Nowak et al., 2008a; Nowak et al. 2008b). Personnel demands, resources, and time need to be taken into consideration. Jaenson et al. (1992) noted that a full inventory conducted in Ithaca, New York, U.S., required a period of five months with a total of six people to finish the 5,600 tree inventory (Bassuk and Jaenson 1988). Jaenson et al. (1992) also noted that a partial inventory could be conducted at a more affordable rate and would only take days instead of months. However, while sampling may be more cost effective and require fewer personnel for a shorter period of time, the protocol (number of plots, size of plots, stratification method, etc.) followed can have an impact on both time and cost effectiveness. Nowak et al. (2008b) conducted research on this subject and noted that the number and size of sample plots are the major factors that urban forest managers need to consider when evaluating the protocols to follow and their effects on the overall costs. Time for data analysis and updating must also be taken into account (Jaenson et al. 1992) when comparing complete with sample inventories. Finally, the amount of time required for checking data integrity will also be affected by the size of the inventory as larger inventories will require more personnel and may even require the help of less qualified individuals (volunteers for example) to aid in data collection.

The United States Department of Agriculture Forest Service (USDA FS) developed a protocol in the 1990s, originally named the Urban Forest Effects (UFORE) model and now referred to as i-Tree Eco (i-Tree 2010a), to be used in conducting tree inventories in urban settings and to provide information on ecosystem services (Nowak and Crane 1998; Nowak et al. 2008a). 
Following this protocol, 200 circular 0.04 ha randomly located plots are assigned in the study area and may include plots with no trees present (Nowak and Crane 1998; Nowak et al. 2008a; Nowak et al. 2008b; i-Tree 2010b; i-Tree 2010c). This sampling protocol was adopted because that was the number of 0.04 ha plots that could be inventoried by a two-person crew in a 14-week summer period and would produce an adequate estimate of the overall population (Nowak et al. 2008b).

i-Tree Eco has been used in multiple cities (Atlanta, Georgia; New York, New York; Philadelphia, Pennsylvania, U.S.) since its development (Nowak et al. 2008a; Nowak et al. 2008b); however, little research has been conducted to validate the plot number parameter for i-Tree Eco (Nowak et al. 2008b). To evaluate the current plot protocol (200 0.04 ha plots), results from a $100 \%$ tree inventory of the Auburn University (AU) campus (Martin 2011) were utilized. The ecosystem services used for this study were air pollution removal, carbon storage, and carbon sequestration. The number of plots with at least one tree present needed to provide an estimate of the total campus value for all three ecosystem services was determined. A range of allowable errors were compared to select a reasonable value based on the premise of the law of diminishing returns (Johnson 2005), as the point where a small decrease in the allowable error would require a large increase in the sample size. Ecosystem services were the main factors used for this study because i-Tree Eco inventories are typically conducted to determine the ecosystem services that are being provided by the urban forest, and the sampling protocol being followed should be one based on the variable(s) of interest. However, the number of trees was also included to provide a comparison to standard i-Tree Eco sampling protocol (Nowak and Crane 1998; Nowak et al. 2008a; Nowak et al. 2008b; i-Tree 2010b; i-Tree 2010c).

\section{MATERIALS AND METHODS}

\section{Study Site}

The study site was the Auburn University campus (32 $36^{\prime} \mathrm{N}$, $85^{\circ} 30^{\prime} \mathrm{W}$ ) located in Auburn, Alabama (Figure 1). The AU main campus encompasses about 306 ha. Managed areas, meaning those locales on a regular maintenance schedule, were the focus of this study, which covered approximately 243 ha, including the Davis Arboretum, covering 5.5 ha.

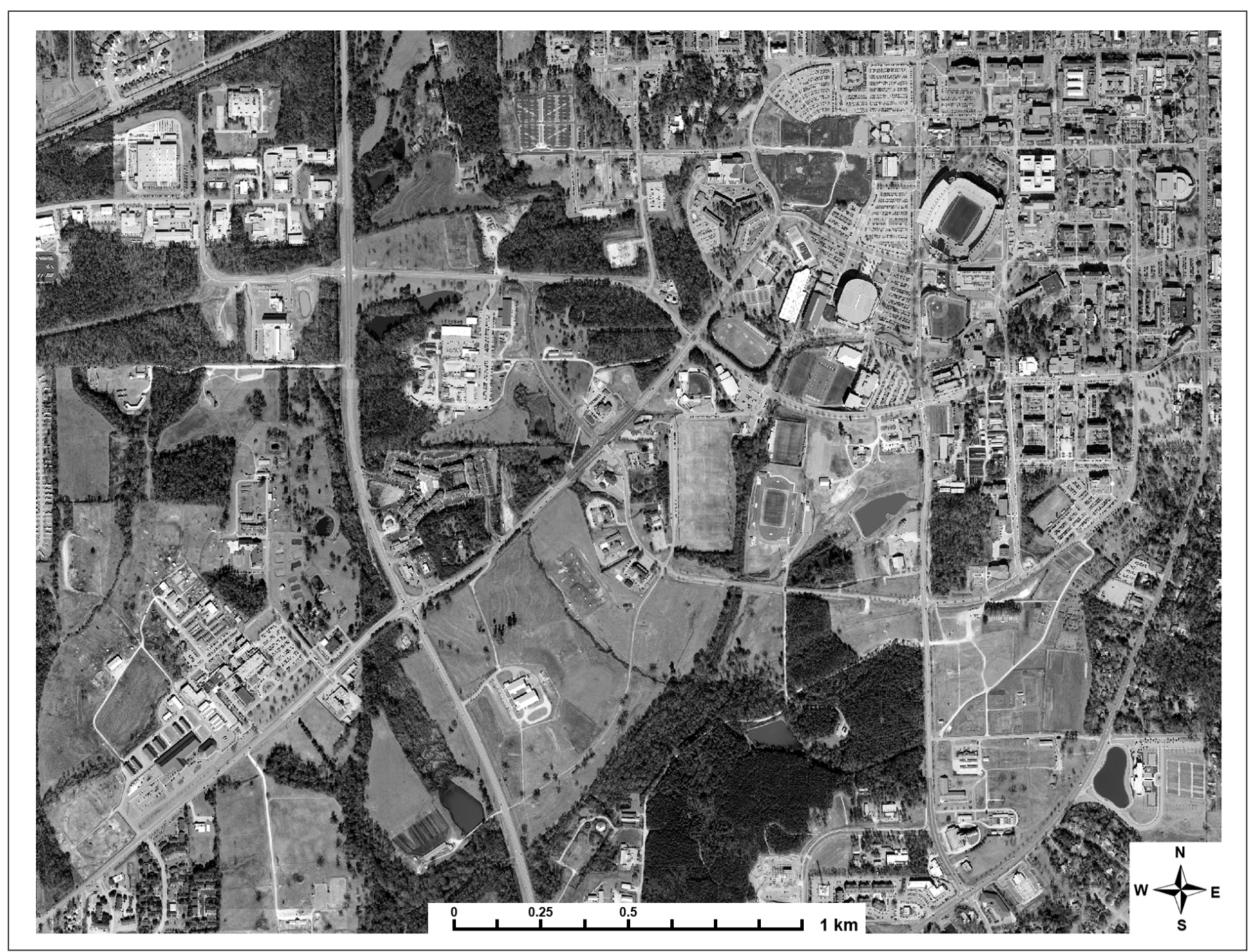

Figure 1. Aerial photograph of the Auburn University campus (spring 2008). 


\section{Inventory}

Field data were collected during a $100 \%$ tree inventory of the AU campus in 2009-2010 (Martin 2011) following i-Tree Eco protocol (i-Tree 2010b; i-Tree 2010c). Sixteen attributes were measured for each tree, including tree species, diameter at breast height (dbh) $(1.37 \mathrm{~m}$ above the ground), tree height, average crown width, dieback, and missing crown. Data collection was completed in May 2010 and all field data were analyzed by the USDA Forest Service which generated information on the ecosystem services provided by the AU urban forest. Information regarding these services included air pollution removal value (USD \$), carbon storage (kilograms), and carbon sequestration (kilograms/year) for each tree. Air pollution removal was considered as a whole instead of evaluating the reported air pollutants individually for the plot number analysis because air pollution was considered as one ecosystem service.

\section{Sampling Design}

All spatial analyses and operations were conducted using the ESRI ArcGIS $^{\circledR} 9$ ArcMap $^{\text {TM }}$ v.9.3 geographic information system (GIS) computer software. First, an aerial photograph of the AU campus was used to create a new shapefile of the boundaries of the study site. No infrastructure (buildings, parking lots, sidewalks) were excluded from the shapefile to provide an accurate picture of the urban environment. All field data and tree locations collected during the initial inventory (Martin 2011) were then used to create a new tree point shapefile with the collected tree data in an associated attribute table. Ecosystem services data for each tree were then appended to the tree attribute table created in the tree point shapefile.

Three thousand random points, created as plot centers, were then generated inside the study area with at least $22.54 \mathrm{~m}$ between the points to ensure that no plots would overlap to meet standard assumptions of random sampling and avoid the complications of trees belonging to more than one plot. The 3,000 plot centers were produced to provide a large enough sample so that the variance between plots could be calculated and produce a sufficient estimate of the proportion of area with trees on the AU campus. A plot covering 0.04 ha was created around each point (plot center). All 0.04 ha plots were then spatially joined with the tree point shapefile created from the inventory field data to select the trees that fell within each plot.

\section{Plot Number Analyses}

For each plot with at least one tree present, air pollution removal, carbon storage, carbon sequestration, and total tree population were determined on a per hectare basis. As with any urban environment, a large proportion of the Auburn campus consists of buildings, roads, and other open areas without trees (about $50 \%$ ). Since plots located in these areas would have plot values of zero for all the factors, this large proportion of zeroes would violate the normality assumption of the random sampling procedure. Therefore, the sample sizes used are for only those areas with trees, excluding those on campus without trees. It is reasonable to assume that areas at least $22.54 \mathrm{~m}$ from the closest tree could be removed from the sampling area by use of the aerial photograph in the GIS map of campus. If not, then the number of plots required to be located randomly across the area would be the number of plots with trees needed to meet the desired allowable error divided by the proportion of the area with trees. For example, if 200 plots with trees are required to meet a desired allowable error of $\pm 10 \%$, and $50 \%$ of the area had no trees, then a total of 400 plots would be needed since $50 \%$ of them would have no trees on them. Likewise any estimate of the ecosystem services would be estimated from only those plots with trees and the total value for the campus would use an estimate of the hectares with trees (120 hectares for the $\mathrm{AU}$ campus). Therefore, only the 1,500 plots with at least one tree were used to estimate the average value per hectare for air pollution removal, carbon storage, carbon sequestration, and number of trees. These plots also provided estimates of variance between plots for each factor. The coefficient of variance was then determined for each factor as the square root of the variance over the average. The number of plots needed to meet a range of allowable errors was then determined using a standard equation for sample size for a finite population of plots, which includes the correction factor for a finite population (Shiver and Borders, 1996). Equations were of the form:

$$
\text { [1] sample size }=\left[4 \mathrm{~A}\left(\mathrm{CV}^{2}\right)\right] /\left[\mathrm{A}\left(\mathrm{E}^{2}\right)+4 \mathrm{P}\left(\mathrm{CV}^{2}\right)\right]
$$

where 4 represents the t-value squared at $\alpha=0.05, \mathrm{~A}$ is the total hectares with trees determined by the total hectares on campus multiplied by the proportion of plots with trees, $\mathrm{CV}$ is the coefficient of variance, $\mathrm{E}$ is the allowable error, and $\mathrm{P}$ is the plot size used for this study, which was a 0.04 ha plot. The range of allowable errors was from $\pm 1 \%$ to $\pm 25 \%$.

\section{RESULTS}

Of the 3,000 plots created, approximately $50 \%$ had at least one tree present. Figure 2 displays how many plots (with at least one tree present) would be necessary (y axis) to achieve an estimate with the desired allowable error of the total campus value ( $\mathrm{x}$ axis) for each factor. Based on the principle of diminishing returns it was decided to use an allowable error of $\pm 10 \%$ because any decrease in the allowable error would require a relatively large increase in the required sample size. To achieve an estimate with a $\pm 10 \%$ allowable error of the total air pollution removal value of the 243 ha AU campus, researchers would require a sample size of 622 plots $(0.04$ ha each) that have at least one tree present. For carbon storage, carbon sequestration, and number of trees it would require: sample sizes of 870,483 , and 258 plots, respectively. Due to the proportion of campus without trees, these sample sizes would be doubled $(1,244 ; 1,740 ; 966$; and 516 , respectively) to incorporate the total number of sample plots needed to be created. It should be noted that the 200 plots recommended in the protocol (i-Tree 2010c) would produce allowable errors of $\pm 19 \%, \pm 24 \%$, $\pm 16 \%$, and $\pm 11 \%$ for total air pollution removal value, carbon storage, carbon sequestration, and number of trees, respectively.

\section{DISCUSSION}

Ecosystem services were used as the basis for a sampling protocol because i-Tree Eco inventories are conducted to quantify the ecosystem services provided by the urban forest to meet specific management objectives. Therefore, sampling should ideally follow a protocol in which the number of plots sampled is based on the ecosystem service(s) of interest so that the inventory is providing accurate results. 


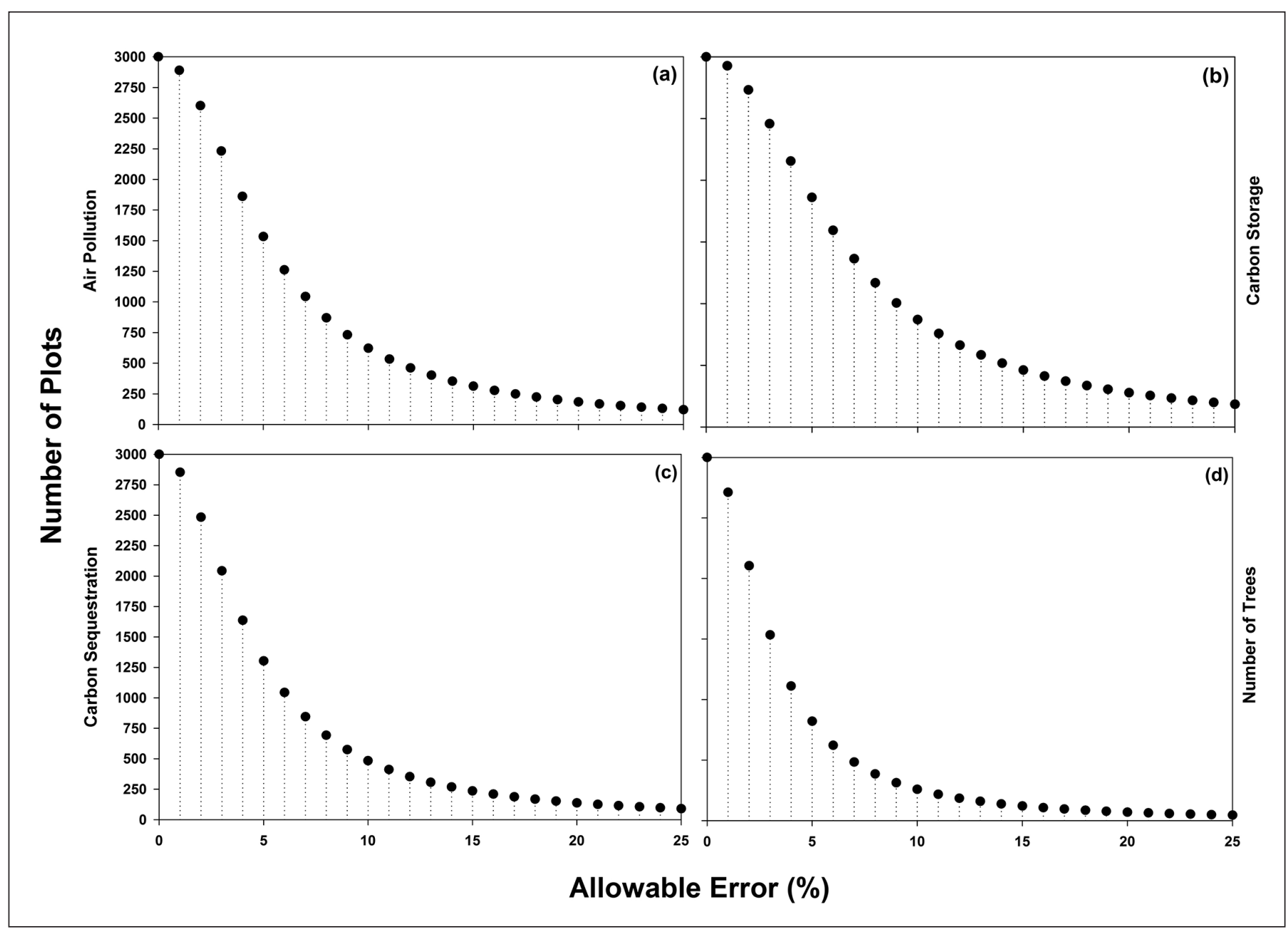

Figure 2. Number of plots required (with at least one tree present) as a function of allowable error for (a) air pollution removal, (b) carbon storage, (c) carbon sequestration, and (d) number of trees.

Following the standard i-Tree Eco sampling protocol (i-Tree 2010b; i-Tree 2010c), Nowak et al. (2008b) found that a $12 \%$ relative standard error (RSE) provided a reasonable estimate of the population. Nowak et al. (2008b) evaluated the effects of different plot sizes not only on the precision of the estimate of the total population but also on time and cost; however, these evaluations did not take into consideration the ecosystem services provided. Researchers of the current study did not evaluate plot size effects to maintain consistency with standard practice using i-Tree Eco. However, future studies should be designed to investigate the influence of plot size on i-Tree Eco sampling protocol.

Results from this study indicate that to achieve an estimate with a $\pm 10 \%$ allowable error for the air pollution removal, carbon storage, and carbon sequestration values for the $\mathrm{AU}$ campus, sampling intensity of approximately $20 \%, 30 \%$, and $16 \%$ of the total area with at least one tree or $10 \%, 15 \%$, and $8 \%$ of the entire campus would be required. According to i-Tree Eco protocol, a 200 plot sample would equate to approximately $3 \%$ of the whole AU campus, including areas with and without trees. However, to achieve a $\pm 10 \%$ allowable error sample sizes of approximately $6 \times, 9 \times$, and $5 \times$ larger than the standard protocol would be needed. The results also indicate that carbon sequestration values can be estimated by the fewest samples fol- lowed by air pollution removal and carbon storage, which would require the most samples. This information could be used by managers to evaluate sampling intensity and associated costs so that the most desirable ecosystem service can be focused on.

The number of trees was also used to determine the necessary number of plots so that a comparison could be made to standard i-Tree Eco protocol (i-Tree 2010b; i-Tree 2010c). Results indicate that a $9 \%$ sample of the total area (258 plots) would be needed to achieve the necessary number of plots to achieve an estimate with a $\pm 10 \%$ allowable error. This sample size would be $1.3 \times$ larger than the standard i-Tree Eco protocol.

Further research is needed concerning this evaluation. These results are for the AU campus and care should be exercised in interpreting the results for a different study site. These results were based on a known tree population (100\% tree inventory) and the proportion of hectares with trees to those without trees. This approach should be tested on several other sites throughout the southern United States to provide the most accurate estimate of number of plots to inventory due in part to differing forest structures, species, and densities present in various urban locales.

Many urban tree inventories have been performed using stratified sampling (Nowak and Crane 1998; Peper et al. 2001a; Peper et al. 2001b; Nowak et al. 2008a), and is an option when using 
i-Tree Eco (i-Tree 2010b). Future research efforts regarding stratification should be conducted to determine the necessary number of plots to be inventoried for each sampling locale to determine the most efficient sampling protocol. Stratification should decrease the coefficient of variance for each strata, thereby reducing the overall sample size needed to meet an allowable error.

\section{CONCLUSION}

As the number of cities and urban areas inventorying their urban forests continues to increase, more research is needed to determine how much of the urban forest must be inventoried to produce an accurate estimate of the total population when a $100 \%$ inventory is not feasible. A sampling protocol used should be based on management objectives. The amount of time available to conduct an inventory and the cost associated with it should be considered when determining what protocol to follow; however, the desired results from the inventory (e.g., ecosystem services) also play a key role. This case study was conducted using a campus setting and begins to validate plot sampling protocol for i-Tree Eco; however, more studies using ecosystem services results from other areas are needed.

Acknowledgments. We would like to thank Dudley Hartel and Eric Kuehler of the USDA Forest Service-Urban Forestry South office for their assistance and guidance during the duration of this project. We would also like to thank Jonathon Bartlett, Mark Caldwell, Andrew Parker, Elliot Glass, Ann Huyler, and Efrem Robbins for their assistance with data collection; James Ransom and Daniel Mullenix for their technical assistance and the Superintendent of Landscape Services, Charlie Crawford, for his assistance throughout the project. This project was funded in part by Auburn University and the USDA Forest Service Co-op Agreement FS-SRS-09-CA-11330150-053.

\section{LITERATURE CITED}

Bassuk, N.L., and R.J. Jaenson. 1988. Ithaca Street Tree Survey. Dept. of Public Works. Ithaca, New York, U.S.

Hauer, R.J., R.W. Miller, and D.M. Ouimet. 1994. Street Tree Decline and Construction Damage. Journal of Arboriculture 20:94-97.

i-Tree. 2010a. i-Tree: Tools for Assessing and Managing Community Forests. <www.itreetools.org >

i-Tree. 2010b. i-Tree Software Suite v4.0 User's Manual. <http://www. itreetools.org/resources/manuals/i-Tree Eco Users Manual.pdf>

i-Tree. 2010c. UFORE Methods. <http://www.itreetools.org/eco/resources/ UFORE\%20Model\%20FAQs.pdf $>$

Jaenson, R., N. Bassuk, S. Schwager, and D. Headley. 1992. A Statistical Method for the Accurate and Rapid Sampling of Urban Street Tree Populations. Journal of Arboriculture 18:171-183.

Johnson, P.M. 2005. A Glossary of Political Economy Terms. <http://www. auburn.edu/ johnspm/gloss/diminishing_returns_law_of>

Martin, N.A., A.H. Chappelka, G.J. Keever, and E.F. Loewenstein. 2011. A $100 \%$ Tree Inventory Using i-Tree Eco Protocol: A Case Study at Auburn University, Alabama. Arboriculture \& Urban Forestry 37(5):207-212.

Martin, N.A. 2011. A 100\% Tree Inventory Using i-Tree Eco Protocol: A Case Study at Auburn University, Alabama. $110 \mathrm{pp}$.

McBride, J.R., and D.J. Nowak. 1989. Urban Park Tree Inventories. Arboricultural Journal 13:345-361.

McPherson, E.G., D. Nowak, G. Heisler, S. Grimmond, C. Souch, R. Grant, and R. Rowntree. 1997. Quantifying Urban Forest Structure,
Function, and Value: The Chicago Urban Forest Climate Project. Urban Ecosystems 1:49-61.

Nowak, D.J., and D.E. Crane. 1998. The Urban Forest Effects (UFORE) Model: Quantifying Urban Forest Structure and Functions. Integrated Tools Proceedings. pp. 714-720.

Nowak, D.J., D.E. Crane, J.C. Stevens, R.E. Hoehn, J.T. Walton, and J. Bond. 2008a. A Ground-Based Method of Assessing Urban Forest Structure and Ecosystem Services. Arboriculture \& Urban Forestry 34:347-358

Nowak, D.J., J.T. Walton, J.C. Stevens, D.E. Crane, and R.E. Hoehn. 2008b. Effect of Plot and Sample Size on Timing and Precision of Urban Forest Assessments. Arboriculture \& Urban Forestry 34:386-390.

Peper, P.J., E.G. McPherson, and S.M. Mori. 2001a. Predictive Equations for Dimensions and Leaf Area of Coastal Southern California Street Trees. Journal of Arboriculture 27:169-180.

Peper, P.J., E.G. McPherson, and S.M. Mori. 2001b. Equations for Predicting Diameter, Height, Crown Width, and Leaf Area of San Joaquin Valley Street Trees. Journal of Arboriculture 27:306-317.

Shiver, B.D., and B.E. Borders. 1996. Sampling Techniques for Forest Resource Inventory. John Wiley \& Sons, Inc., New York, New York, U.S. $356 \mathrm{pp}$.

Welch, J.M. 1994. Street and Park Trees of Boston: A Comparison of Urban Forest Structure. Landscape and Urban Planning 29:131-143.

Nicholas A. Martin (corresponding author)

School of Forestry and Wildlife Sciences

Auburn University

Auburn, AL 36849, U.S.

nmartin@bartlett.com

Inventory Arborist

Bartlett Tree Experts

13768 Hamilton Road

Charlotte, North Carolina 28278, U.S.

Arthur H. Chappelka

School of Forestry and Wildlife Sciences

Auburn University

Auburn, Alabama 36849, U.S.

chappah@auburn.edu

Greg Somers

School of Forestry and Wildlife Sciences

Auburn University

Auburn, Alabama 36849, U.S.

somergl@auburn.edu

Edward F. Loewenstein

School of Forestry and Wildlife Sciences

Auburn University

Auburn, Alabama 36849, U.S.

loewenstein@auburn.edu

Gary J. Keever

Department of Horticulture

Auburn University

Auburn, Alabama 36849, U.S.

keevegj@auburn.edu 
Zusammenfassung. Die Auburn Universität in Auburn, Alabama, U.S. wurde als Standort für eine Fallstudie im Rahmen der Wertermittlung des Standarterfassungsprotokolls in dem i-Tree Eco-Programm ausgewählt. In 2009 bis 2010 wurde ein 100\%iges Baumkataster aller gepflegten Campusbereiche durchgeführt und man erhielt einen kompletten Datensatz für die Bewertung. Die untersuchten Ökosystemleistungen waren Reduzierung der Luftverschmutzung, Kohlenstoffspeicherung und Kohlenstoffbindung. Die gesamte Baumpopulation wurde für diese Untersuchung ebenfalls herangezogen, um einen Vergleich zum i-Tree Eco Protokoll zu liefern. Um eine Schätzung mit +/- 10\% Fehlertoleranz für den Gesamtwert des Campus zu erzielen, würden 622 Plots (je 0,04 ha) mit mindestens einem Baum für die Beseitigung der Luftverschmutzung untersucht werden müssen, 870 Plots für Kohlenstoffspeicherung, 483 Plots für Kohlenstoffbindung und 258 Plots für die Anzahl der Bäume, im Gegensatz zum Standart i-Tree Eco Protokoll von 200 Bäumen. Diese Studie ist ein erster Schritt in der Bewertung des i-Tree Eco Protokolls, dennoch sind mehr Anstrengungen nötig, diese Ergebnisse an Standorten in den südlichen Vereinigten Staaten zu testen, um akkurate Schätzungen der erforderlichen Anzahl der Teststandorte zur späteren Vorhersage der Ökosystemleistungen der urbanen Forstflächen zu liefern.

Resumen. La universidad de Auburn (Auburn, Alabama, EE.UU.) se utilizó como sitio para un estudio de caso de la evaluación de la parcela de muestreo protocolo estándar para Eco i-Tree. Se llevó a cabo un inventario de árboles al 100\% de las áreas de manejo de la escuela en el período 2009-2010 y se obtuvo un conjunto completo de datos para la evaluación. La remoción de la contaminación atmosférica, el almacenamiento de carbono y la captura del mismo fueron los servicios de los ecosistemas examinados. La población total de los árboles también fue utilizada para esta evaluación para proporcionar una comparación con el protocolo i-Tree Eco. Para lograr una estimación, con un $\pm 10 \%$ de error aceptable para el valor total de campus, se necesitaron 622 parcelas ( 0,04 ha cada una) con la presencia de por lo menos un árbol que tendrían que ser inventariados para la remoción de la contaminación del aire, 870 parcelas de almacenamiento de carbono, 483 parcelas de secuestro de carbono y 258 parcelas para el número de árboles, en comparación con el protocolo estándar i-Tree Eco de 200 parcelas. Este estudio ofrece un primer paso en la evaluación del protocolo de muestreo i-Tree Eco; sin embargo, son necesarios los esfuerzos de pruebas en los lugares de todo el sur de los Estados Unidos para proporcionar una estimación más precisa del número de parcelas necesarias para la predicción de servicios de los ecosistemas de bosques urbanos. 